\title{
Investigation on the Pattern Synthesis of Subarray Weights for Low EMI Applications
}

\author{
T Vidhyavathi ${ }^{1}$, G S N Raju ${ }^{2}$, G V K Varma ${ }^{3}$ \\ ${ }^{I}$ Department of ECE, Gayatri Vidya parishad College of Engineering (Autonomous), Visakhapatnam, \\ Andhrapradesh, India. \\ ${ }^{2}$ Department of ECE, Andhra University college of Engineering (Autonomous), Visakhapatnam, \\ Andhrapradesh, India. \\ ${ }^{3}$ Sr. Engineer, Qual.comm, Sandiego, California, USA
}

\begin{abstract}
In modern radar applications, it is frequently required to produce sum and difference patterns sequentially. The sum pattern amplitude coefficients are obtained by using Dolph-Chebyshev synthesis method where as the difference pattern excitation coefficients will be optimized in this present work. For this purpose optimal group weights will be introduced to the different array elements to obtain any type of beam depending on the application. Optimization of excitation to the array elements is the main objective so in this process a subarray configuration is adopted. However, Differential Evolution Algorithm is applied for optimization method. The proposed method is reliable and accurate. It is superior to other methods in terms of convergence speed and robustness. Numerical and simulation results are presented.
\end{abstract}

Key Words: Antenna Arrays, Sum and Difference, Pattern Synthesis, Subarray weighting configuration, Ultra Sidelobe level suppression, Differential Evolution Method.

\section{Introduction}

The concepts of half-power beamwidth and peak directivity of a linear antenna array pattern are introduced and it is applied to the case of pattern synthesis. For this purpose a well known technique called Dolph-Chebyshev synthesis method [1] is widely used. Namara [2] proposed the excitation matching method based on an expansion in terms of Zolotarev polynomials where each possible grouping, the corresponding subarray coefficients are iteratively computed.

The design of monopulse radar systems [3]-[4] requires the synthesis of both the sum and the difference pattern, which satisfy some specifications such as narrow beamwidth, low sidelobe level (SLL) and high directivity. In order to properly solve the optimal compromise problem in monopulse radar tracking array antennas, several techniques [5]-[6] based on sub arraying have been proposed to reduce the design complexity of the feed network. Shindman et al. [7] developed the techniques for designing the minimum power sidelobes for a main lobe array factor or difference pattern array factor. Although several methods [8]-[10] for implementing monopulse antennas have been proposed, interest has been shown to the methods that use proper feed networks for the design of a single feed for both sum and difference patterns instead to two independent feeds.

Differential Evolution Algorithm (DEA) is most powerful global optimizer and has been successfully applied to array pattern synthesis and also in other areas of the applied electromagnetic problems. In addition to the above, proper amplitude excitation weights of the elements are used to control the beam width and sidelobe level [11]-[12].

The sum pattern amplitude coefficients are obtained by using Dolph-Chebyshev synthesis method where as the difference pattern excitation coefficients will be optimized in this present work. For this purpose optimal group weights will be introduced to the different array elements to obtain any type of beam depending on the application. Optimization of excitation to the array elements is the main objective so in this process a subarray configuration is used to reduce the design complexity of feeding network.

The excitation coefficients for the sum pattern are calculated from the Dolph-Chebyshev method with fixed SLL $=-40 \mathrm{~dB}$. This problem has already studied and final difference pattern was optimized by Differential Evolution Strategy (DES).

2.1. Initialization:

\section{Differential Evolution Algorithm}

Differential Evolution is very simple to understand and easy to implement, which begins with a population of D dimensional vectors and denotes by $\mathrm{N}_{\mathrm{s}}$ shown in the following equation (1)

$$
\mathrm{X}_{\mathrm{i}, \mathrm{G}}, \mathrm{i}=1,2, \ldots, \mathrm{N}_{\mathrm{s}}
$$


Where the index ' $i$ ' denotes the population and ' $G$ ' denotes the generation to which the population belongs. DE strategy depends on three main operators that are mutation, crossover and selection. Schematic representation of DE strategy is shown in the figure 1.

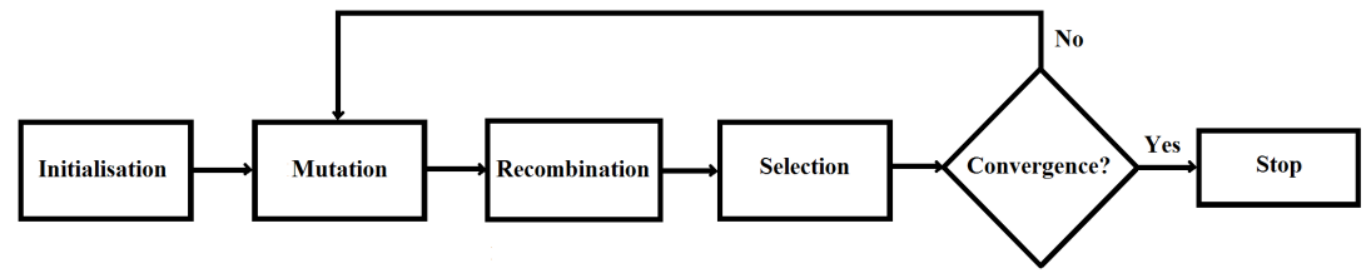

Figure 1: Schematic Representation of DE Strategy.

\subsection{Mutation:}

The mutation process at each generation begins by randomly selecting three individual variables that are $\mathrm{X}_{\mathrm{r}_{1}}, \mathrm{X}_{\mathrm{r}_{2}}, \mathrm{X}_{\mathrm{r}_{3}}$ in the population set of $\mathrm{N}_{\mathrm{s}}$ elements.

For each target vector $X_{i, G}$, a mutant vector is generated according to the following equation

$$
\mathrm{V}_{\mathrm{iG}+1}=\mathrm{X}_{\mathrm{i}, \mathrm{G}}+\mathrm{F} \cdot\left(\mathrm{X}_{\mathrm{r}_{2}, \mathrm{G}}-\mathrm{X}_{\mathrm{r}_{3}, \mathrm{G}}\right)
$$

Where the indexes $r_{1}, r_{2}, r_{3} \in\left\{1,2,3 \ldots N_{s}\right\}$ are randomly selected such that $r_{1} \neq r_{2} \neq r_{3} \neq i$, F is a real and constant factor $€[0,2]$ which controls the strengthening of the discrepancy variation $\left(\mathrm{X}_{\mathrm{r}_{2}, \mathrm{G}}-\mathrm{X}_{\mathrm{r}_{3}, \mathrm{G}}\right)$.

\subsection{Crossover:}

Once mutation part is completed, in order to increase the range of the perturbed parameter vectors crossover is introduced. In this stage the parent vector is mixed with the mutated vector to produce a trail vector $U_{j i, G+1}$. The trail vector is described as follows.

$$
\begin{gathered}
U_{\mathrm{i}, \mathrm{G}+1}=\left(\mathrm{U}_{1 \mathrm{i}, \mathrm{G}+1}, \mathrm{U}_{2 \mathrm{i}, \mathrm{G}+1}, \ldots \ldots, \mathrm{U}_{\mathrm{Di}, \mathrm{G}+1}\right) \\
\mathrm{U}_{\mathrm{ji}, \mathrm{G}+1}=\left\{\begin{array}{ll}
\mathrm{V}_{\mathrm{ji}, \mathrm{G}+1} & \text { if }\left(\operatorname{randm} \mathrm{b}(\mathrm{j}) \leq \mathrm{C}_{\mathrm{R}}\right) \text { or } \mathrm{j}=\mathrm{k} \\
\mathrm{X}_{\mathrm{ji}, \mathrm{G}} & \text { if }\left(\operatorname{randm} \mathrm{b}(\mathrm{j})>\mathrm{C}_{\mathrm{R}}\right) \text { or } \mathrm{j} \neq \mathrm{k}
\end{array}\right\}
\end{gathered}
$$

Where $\mathrm{j} \in\{1,2 \ldots \mathrm{D}\}, \mathrm{k}$ is a random parameter index chosen once for each ' $\mathrm{i}$ '.

$\mathrm{C}_{\mathrm{R}}$ is the crossover constant $\mathrm{C}[0,1]$.

randm $b(j)$ is the $j^{\text {th }}$ evaluation of a uniform random number generator with outcome $\epsilon[0,1]$. Figure 2 gives an example of crossover mechanism for 7-dimensional vectors.

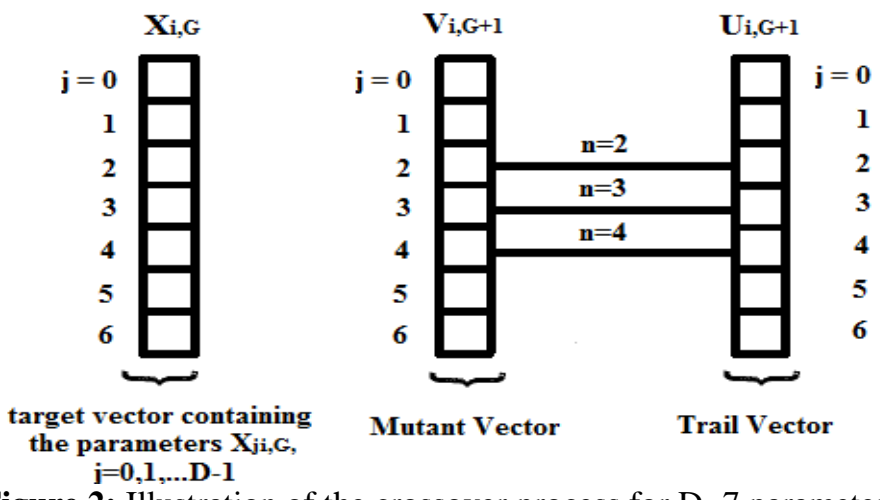

Figure 2: Illustration of the crossover process for $\mathrm{D}=7$ parameters.

\subsection{Selection:}

Selection takes place with a contest held between the one with best fitness function and the target vector, which are allowed to enter the next generation. The trail vector $\mathrm{U}_{\mathrm{i}, \mathrm{G}+1}$ is compared to the target vector $\mathrm{X}_{\mathrm{i}, \mathrm{G}}$ using the greedy criterion to decide whether it should become a member of generation $\mathrm{G}+1$ or not. Population for the next generation is selected according to the following rule.

Where $\mathrm{j}=1,2,3 \ldots \mathrm{N}_{\mathrm{s}}$.

$$
\mathrm{X}_{\mathrm{i}, \mathrm{G}+1}=\left\{\begin{array}{lr}
\mathrm{U}_{\mathrm{i}, \mathrm{G}+1} & \text { if } \mathrm{f}\left(\mathrm{U}_{\mathrm{i}, \mathrm{G}+1}\right) \leq \mathrm{f}\left(\mathrm{X}_{\mathrm{i}, \mathrm{G}}\right) \\
\mathrm{X}_{\mathrm{i}, \mathrm{G}} & \text { otherwise }
\end{array}\right\}
$$

For this problem, the $\mathrm{i}^{\text {th }}$ element of the population at the $\mathrm{k}^{\text {th }}$ iteration is indicated by $\mathrm{V}_{\mathrm{k}}(\mathrm{i}),\left(\mathrm{i}=1, \ldots, \mathrm{N}_{\mathrm{s}}\right)$, which has the following hybrid structure with integer and real variables $V_{k}(i)=\left(g_{1} \ldots g_{p}, c_{1} \ldots c_{N}\right)$. The key Parameters of the DE algorithm $C_{R}$ and $F$ should be accurately chosen in order to avoid a premature convergence to local minima or to a slow convergence rate. 


\section{Mathematical Formulation}

\subsection{Dolph-Chebyshev Array Design Procedure:}

Consider an array of isotropic elements positioned symmetrically along the $\mathrm{X}$-axis. Suppose the distance between any two adjacent elements is ' $\mathrm{d}$ ', and the array is operated at $\lambda / 2$, a symmetric linear array is shown in figure 3 .

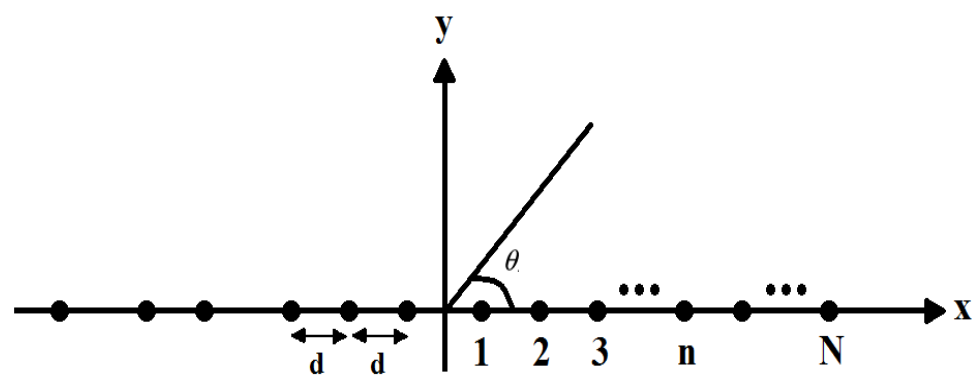

Figure 3: Geometry for $\mathrm{N}$ element linear array

Its excitation coefficients are related to Tchebyshev polynomials. The recursion formula for $\mathrm{r}^{\text {th }}$ Tchebyshev polynomial $\mathrm{T}_{\mathrm{r}}(\mathrm{z})$ is given below

$$
\mathrm{T}_{\mathrm{r}}(\mathrm{z})=2 \mathrm{z}_{\mathrm{r}-1}(\mathrm{z})-\mathrm{T}_{\mathrm{r}-2}(\mathrm{z})
$$

Here every polynomial can also be computed using

$$
\begin{array}{cl}
\mathrm{T}_{\mathrm{r}}(\mathrm{z})=\cos \left(\mathrm{r}^{-\cos ^{-1}}(\mathrm{z})\right) & -1 \leq \mathrm{z} \leq+1 \\
\mathrm{~T}_{\mathrm{r}}(\mathrm{z})=\cos \left(\mathrm{r} \cosh ^{-1}(\mathrm{z})\right) & \mathrm{z}<-1, \mathrm{z}>+1
\end{array}
$$

With this symmetric amplitude excitation the array factor of an array with even or odd number of elements is more than a sum of cosine terms.

To show the approach, consider a linear array of $\mathrm{N}$ equally-spaced elements whose array factor $\mathrm{AF}(\theta)$.

$$
(A F)_{N}=\sum_{n=1}^{M} a_{n} \cos [2(n-1) u] \quad N=2 M(\text { even })
$$

Where,

$$
\mathrm{u}=\frac{\pi \mathrm{d}}{\lambda} \cos \theta
$$

' $\mathrm{a}_{\mathrm{n}}$ ' are the amplitude excitation coefficients

' $\lambda$ ' is wave length in integer times of fundamental frequency,

' $\theta$ ' defines the angle at which $\operatorname{AF}(\theta)$ is calculated with respect to the broadside direction.

' $\mathrm{d}$ ' is the inter-element distance,

' $M$ ' the number of elements.

\subsection{Array synthesis methodology:}

The objective of the synthesis is to construct a reduced subarray configuration able to synthesize as better as possible this pattern. To avoid the implementation of several designing network arrays, a subarray configuration is adopted. The sum Pattern of array factor $\mathrm{AF}_{\mathrm{s}}(\theta)$ is obtained starting by a set of excitation coefficients, $\mathrm{a}_{\mathrm{n}}^{\mathrm{s}}$, $(\mathrm{n}=-\mathrm{N} . \ldots-1,1, \ldots, \mathrm{N})$ which are assumed to be symmetric i.e., $\mathrm{a}_{-\mathrm{n}}{ }^{\mathrm{s}}=\mathrm{a}_{\mathrm{n}}{ }^{\mathrm{s}},(\mathrm{n}=1, \ldots, \mathrm{N})$ and are fixed. In this case, the array space factor is given by

$$
\mathrm{AF}_{\mathrm{s}}(\theta)=\sum_{\mathrm{n}=1}^{\mathrm{N}} \mathrm{a}_{\mathrm{n}}^{\mathrm{s}}{ }^{\mathrm{s}} \cos \left[\frac{1}{2}(2 \mathrm{n}-1) \mathrm{kd} \cos \theta\right]
$$

The ' $\mathrm{N}$ ' number of elements for the array is grouped into ' $\mathrm{P}$ ' subarrays in order to construct the difference pattern. Each subarray has a weighting coefficient $\mathrm{g}_{\mathrm{c}_{\mathrm{n}}}, \mathrm{p}=1, \ldots, \mathrm{P}$, and in order to create a difference pattern, the group of the antennas must be optimized.

In particular, if $c_{n}=p$, then the $n^{\text {th }}$ element is to be connected to the $p^{\text {th }}$ subarray. If $c_{n}=0$, then the element is not considered in the process of synthesis.

The excitation coefficients of the difference pattern can be obtained by multiplying each coefficient of the sum pattern to the coefficient of the corresponding subarray group weight

Formally,

$\mathrm{a}_{\mathrm{n}}^{\mathrm{d}}=\mathrm{g}_{\mathrm{c}_{\mathrm{n}}} \cdot \mathrm{a}_{\mathrm{n}}^{\mathrm{s}}, \quad \mathrm{c}_{\mathrm{n}}=1, \ldots, \mathrm{p}, \ldots \mathrm{P}$.

Here $g_{c_{n}}$ denotes the Kronecker function, i.e.,

$$
\left\{\begin{array}{ll}
g_{c_{n}}=1 & \text { if } c_{n}=p \\
g_{c_{n}}=0 & \text { elsewhere }
\end{array}\right\}
$$


Where $g_{p}$ is the group weight of the $\mathrm{p}^{\text {th }}$ subarray.

A typical configuration for a subarrayed linear array structure with $\mathrm{N}$ isotropic elements for sum pattern excitation levels of $a_{n}{ }^{\mathrm{S}}$ and difference pattern excitation levels of $\mathrm{a}_{\mathrm{n}}{ }^{\mathrm{d}}$ are shown in figure 4 .

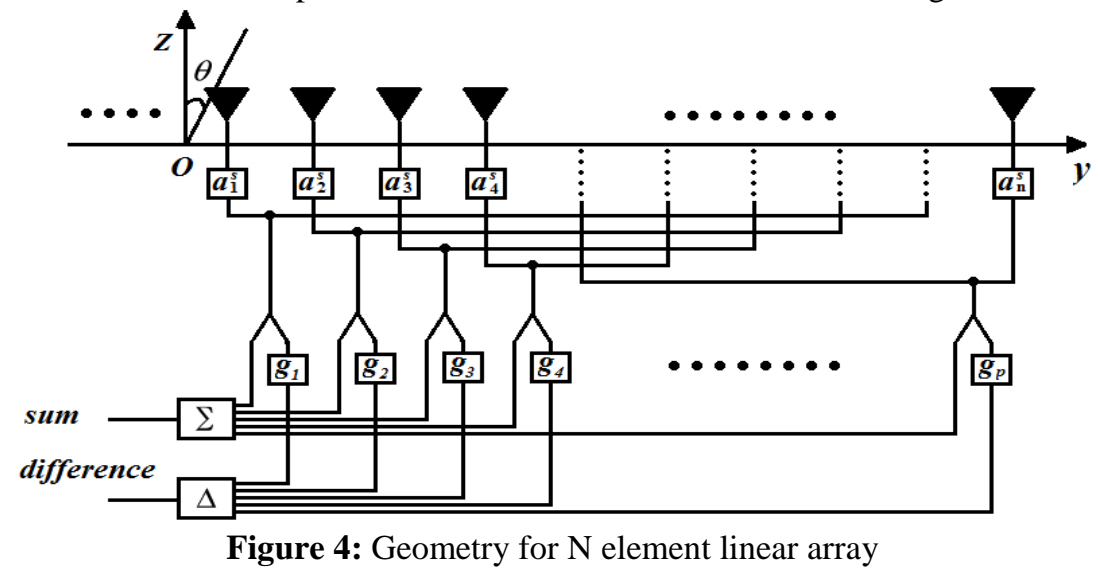

Due to the problem of symmetry, only one half of the array is considered in the synthesis problem. In particular, the elements of the array are grouped in to 'P' subarrays. Since the excitations of the difference pattern must be antisymmetric, i.e. $\mathrm{a}_{-\mathrm{n}}{ }^{\mathrm{d}}=-\mathrm{a}_{\mathrm{n}}{ }^{\mathrm{d}},(\mathrm{n}=1, \ldots, \mathrm{N})$ to ensure a deep null at the broad side. In this case, the array space factor is given by

$$
\mathrm{AF}_{\mathrm{d}}(\theta)=\sum_{\mathrm{n}=1}^{\mathrm{N}} \mathrm{a}_{\mathrm{n}}{ }^{\mathrm{d}} \sin \left[\frac{1}{2}(2 \mathrm{n}-1) \mathrm{kd} \cos \theta\right]
$$

Where ' $\mathrm{k}$ ' is a wave number of the propagation medium equals to $2 \pi / \lambda$

$a_{n}{ }^{s}$ Amplitude sum pattern excitation coefficients,

$\mathrm{a}_{\mathrm{n}}{ }_{\mathrm{d}}^{\mathrm{d}}$ Amplitude difference pattern excitation coefficients, and

' $\theta$ ' defines the angle at which ' $F$ ' is calculated with respect to a direction orthogonal to the array.

The sum patterns are obtained for SLL $=-40 \mathrm{~dB}$ and the difference patterns are achieved using proposed method. This problem can now be deal with an optimization, where the clustering into subarrays ' $\mathrm{c}_{\mathrm{n}}$ ' and the subarray group weights ' $\mathrm{g}_{\mathrm{p}}$ ' are the optimization variables in order to optimize the difference pattern with maximum directivity. Specifications such as Sidelobe levels and beamwidth for the difference pattern can be optimized with a proper selection of the element grouping and subarray weights. Only half of the array is needed to be considered, since both the patterns are symmetric. The optimized radiation patterns are obtained with fixed SLL's for various numbers of subarrays.

\subsection{Objective function:}

To this end, the optimized objective function used for calculating the fitness function associated with the symmetrical linear array can be formulated as follows

$$
\begin{gathered}
\text { Fitness }=\mathrm{PSLL}_{0}-\mathrm{SLL}_{\mathrm{d}} \\
\text { Where } \quad \mathrm{PSLL}_{0}=\operatorname{Max}_{\forall \theta \in S}\left[20 \log _{10}\left|\frac{\mathrm{E}(\theta)}{\mathrm{E}_{\max }(\theta)}\right|\right]
\end{gathered}
$$

$\mathrm{SLL}_{\mathrm{d}}=$ Desired sidelobe level

$E_{\max }(\theta)=$ Peak value of the Main beam

$' \theta '=$ Steering angle from the broad side of the array, $-90 \leq \theta \leq 90$

' $\mathrm{S}$ ' = Space spanned by the angle excluding the mainlobe.

\section{Numerical Simulation Results And Discussions}

In order to validate the effectiveness of Differential Evolution Method we first examine a linear array with 8 subarrays of 40 elements and 60 elements that are spaced $\lambda / 2$ distance apart. The excitations for the sum pattern $\mathrm{a}_{\mathrm{n}}{ }^{\mathrm{s}}$ are calculated from the dolph-chebyshev method using equation (8) with SLL=-40dB.

In order to construct the difference pattern, the $\mathrm{N}$ number of elements for the array is grouped into $\mathrm{P}$ subarrays. The excitations for the difference pattern $\mathrm{a}_{\mathrm{n}}{ }^{\mathrm{d}}$ are determined by using differential evolution with the equation (9). Figure (5) reports the behavior of the cost function versus the number of iterations.

First investigate a linear array of 40 and 60 elements that are spaced $\lambda / 2$ distance apart with 8 sub arrays for sum $S L L=-40 \mathrm{~dB}$. The optimized radiation patterns of difference array space factor for 8 subarrays are obtained by using the equation (11) and the results are shown in figure (6) and figure (10). As can be seen from these 
figures, the resulting first SLL's for difference pattern is reduced to $F S L L=-54.53 \mathrm{~dB}$ and $\mathrm{FSLL}=-54.91 \mathrm{~dB}$ for 40 and 60 elements.

The radiation patterns of 40, 60 elements for 10, 6, 4, 2 subarrays are computed that are reported in figures (7), (8) and figures (11), (12) and also the corresponding subbarray configurations and its group weights are listed in tables (1), (2), (3) and (4).

Finally, for completeness, table (5) presented that 10 subarrays of difference pattern of reduced FSLL=$54.97 \mathrm{~dB}$ and table shows that the number of elements increases for increased subarrays, the difference patterns of FSLL's may be reduced. So finally DES has a more robust exploration ability to reach the optimal point in the search space.

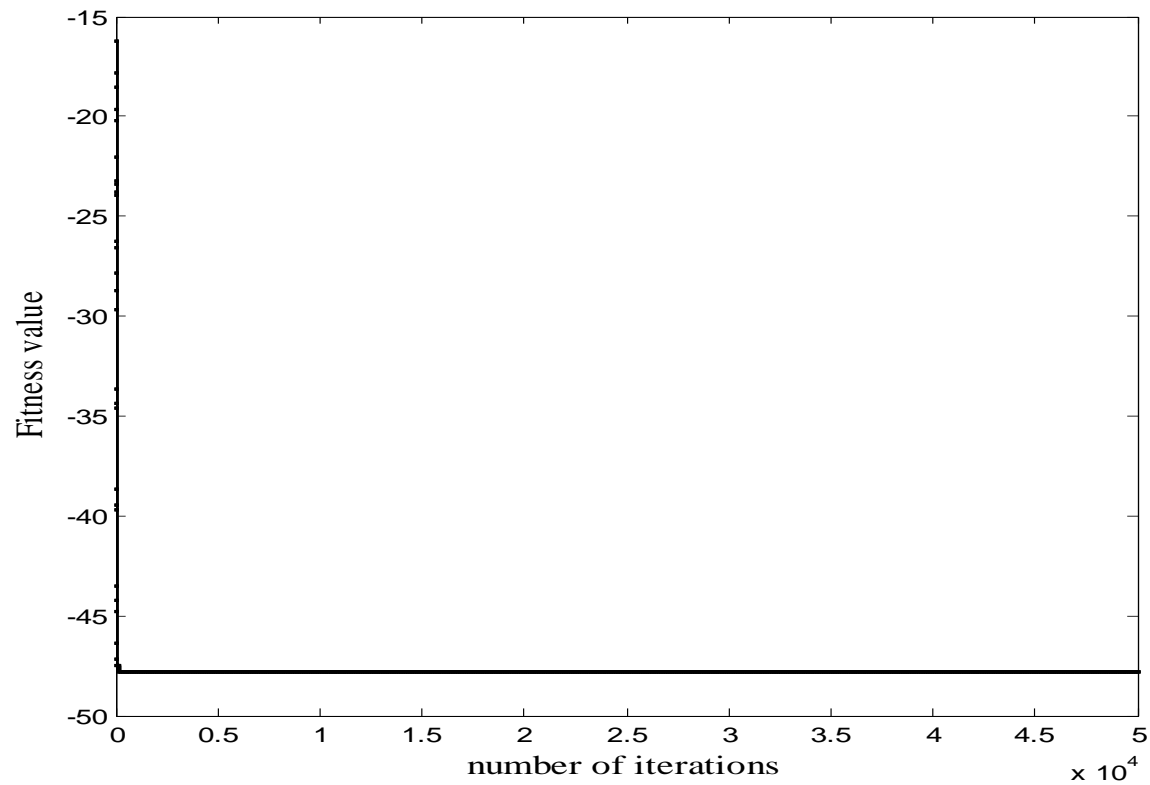

Figure: 5 Behavior of fitness function of 40 elements with SLL $=-40 \mathrm{~dB}$.

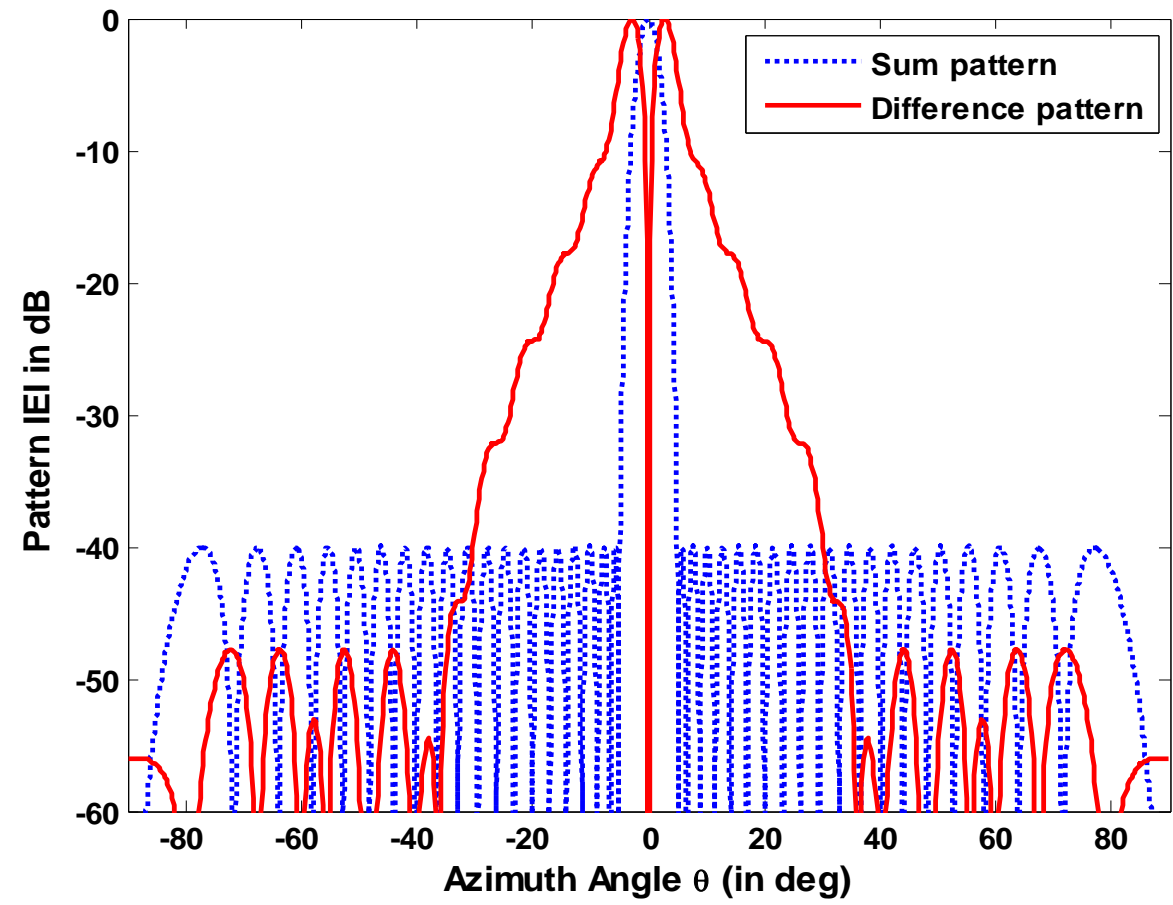

Figure: 6 Sum pattern for a 40 elements Dolph-chebyshev array space factor with SLL=-40dB and the corresponding optimized difference pattern for $\mathrm{P}=8$ subarrays 


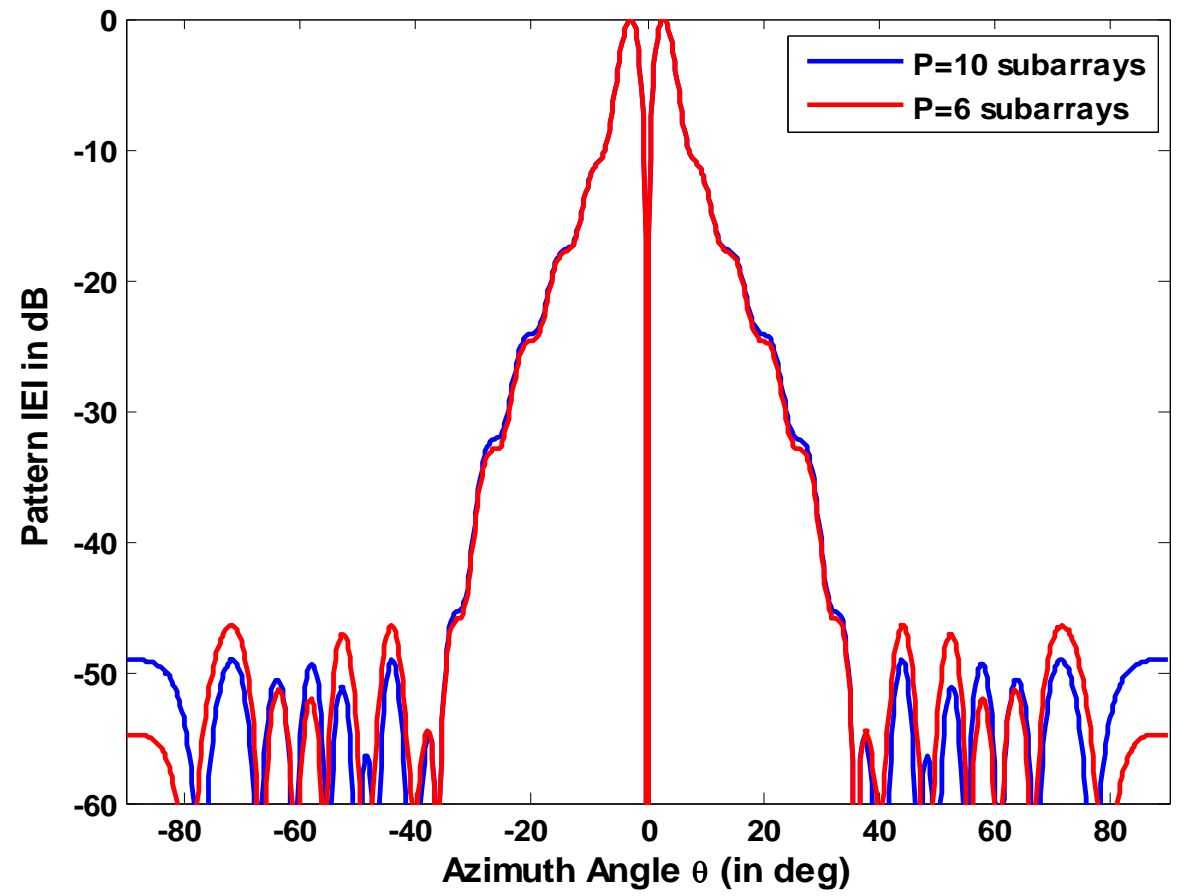

Figure: 7 optimized difference patterns for various values of $P$ obtained by DE when the sum pattern is predetermined from the Dolph-chebyshev synthesis.

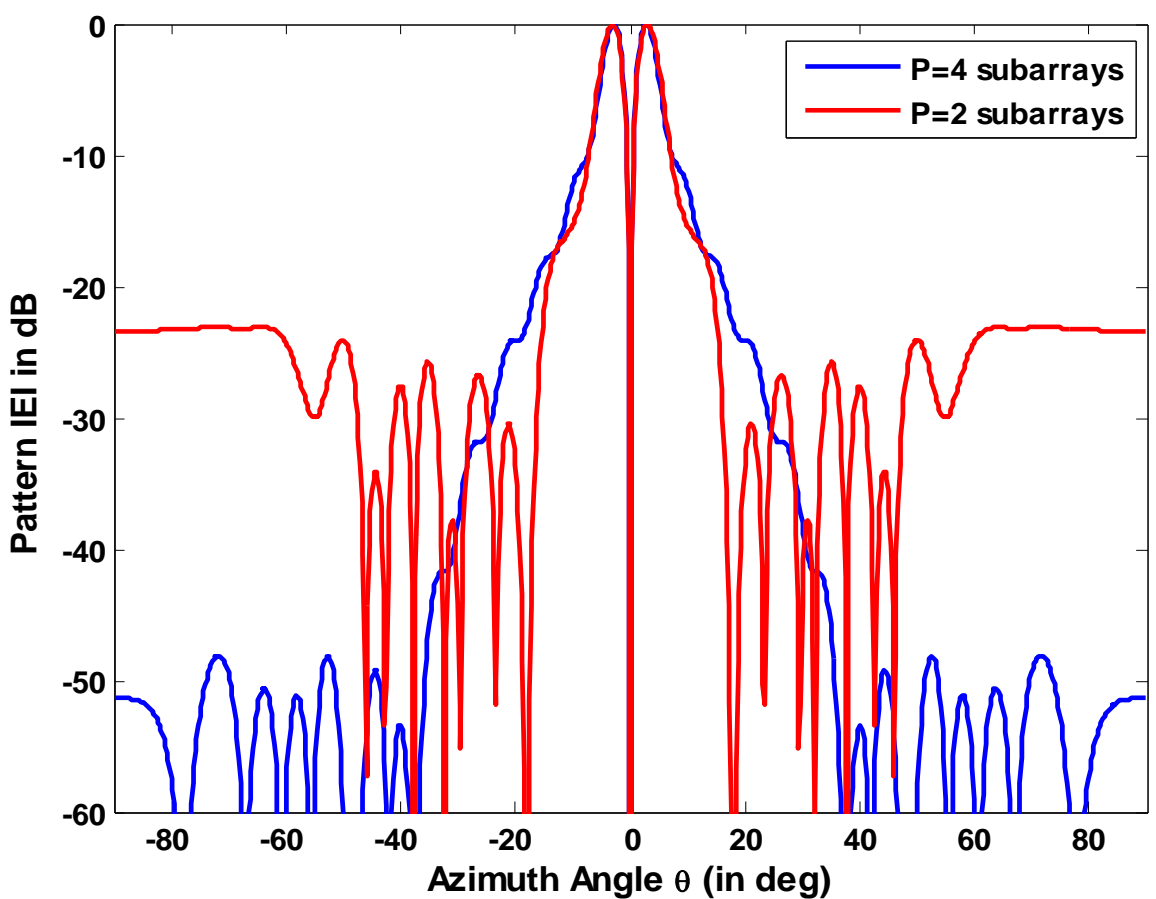

Figure: $\mathbf{8}$ optimized difference patterns for various values of $\mathrm{P}$ obtained by DE when the sum pattern is predetermined from the Dolph-chebyshev synthesis.

Table: 1: Subarray configurations of 40 element with SLL $=-40 \mathrm{~dB}$

\begin{tabular}{|c|c|}
\hline Subarray number & Optimal clustering in to subarrays and here showing only half of the array \\
\hline $\mathrm{P}=10$ & {$[10,2,1,1,7,5,8,1,1,5,1,1,1,1,1,1,1,1,2,10]$} \\
\hline $\mathrm{P}=8$ & {$[3,5,8,8,8,1,1,2,1,8,1,8,1,2,1,1,8,1,5,3]$} \\
\hline $\mathrm{P}=6$ & {$[4,3,2,1,6,6,6,1,5,6,1,6,6,2,1,2,1,1,3,4]$} \\
\hline $\mathrm{P}=4$ & {$[2,3,1,4,4,4,4,4,1,1,1,1,4,4,1,1,4,1,3,2]$} \\
\hline $\mathrm{P}=2$ & {$[2,2,1,1,1,1,1,1,1,1,1,1,1,1,2,2,1,2,2,2]$} \\
\hline
\end{tabular}


Table: 2 Subarray weights for the arrays described in table 1

\begin{tabular}{|c|c|c|c|c|c|}
\hline & $\mathrm{P}=10$ & $\mathrm{P}=8$ & $\mathrm{P}=6$ & $\mathrm{P}=4$ & $\mathrm{P}=2$ \\
\hline G1 & 1.0000 & 0 & 1.0000 & 0.9957 & 0.8359 \\
\hline G2 & 0.8056 & 0.9955 & 1.0000 & 0.3213 & 0.3281 \\
\hline G3 & 1.0000 & 0.3120 & 0.7958 & 0.8105 & \\
\hline G4 & 0 & 1.0000 & 0.3084 & 1.0000 & \\
\hline G5 & 1.0000 & 0.8028 & 0 & & \\
\hline G6 & 1.0000 & 1.0000 & 1.0000 & & \\
\hline G7 & 0.9885 & 0 & & & \\
\hline G9 & 0 & 0.9969 & & & \\
\hline G10 & 0.3164 & & & & \\
\hline
\end{tabular}

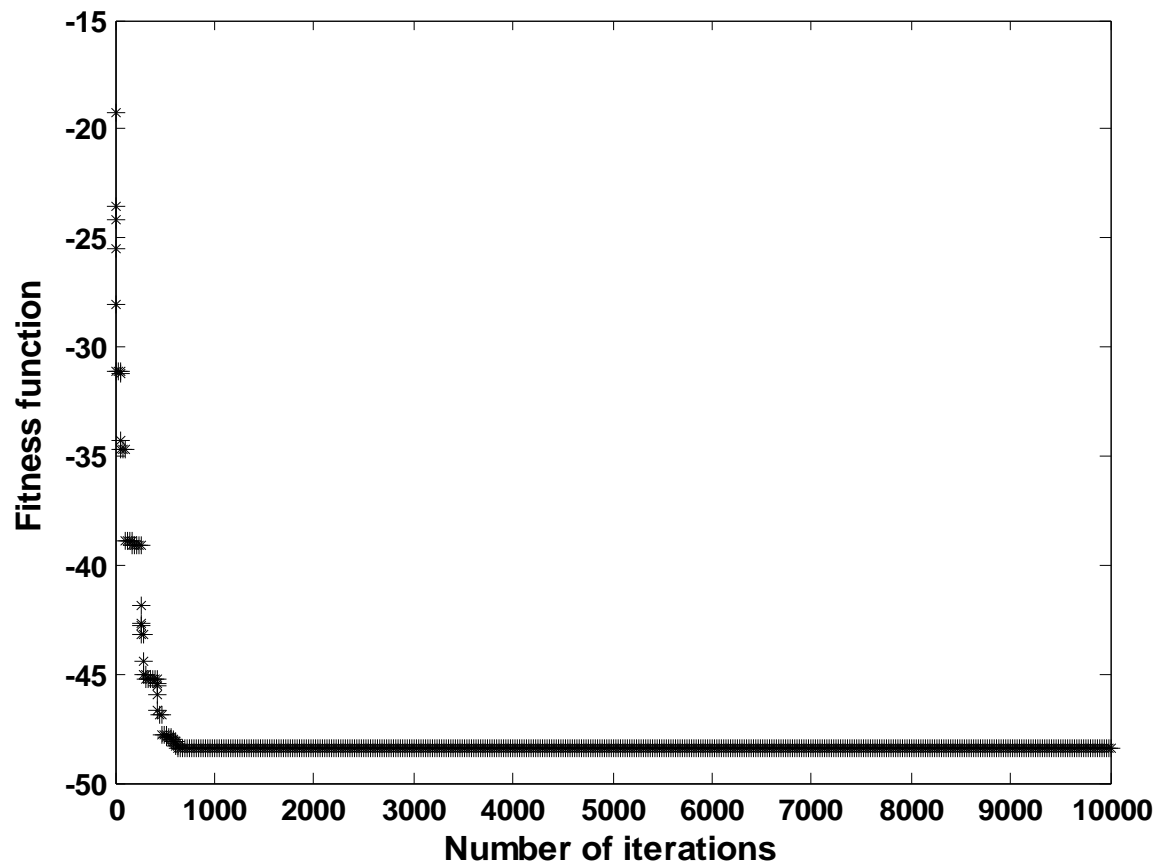

Figure: 9 Behavior of fitness function of 60 elements with $\mathrm{SLL}=-40 \mathrm{~dB}$.

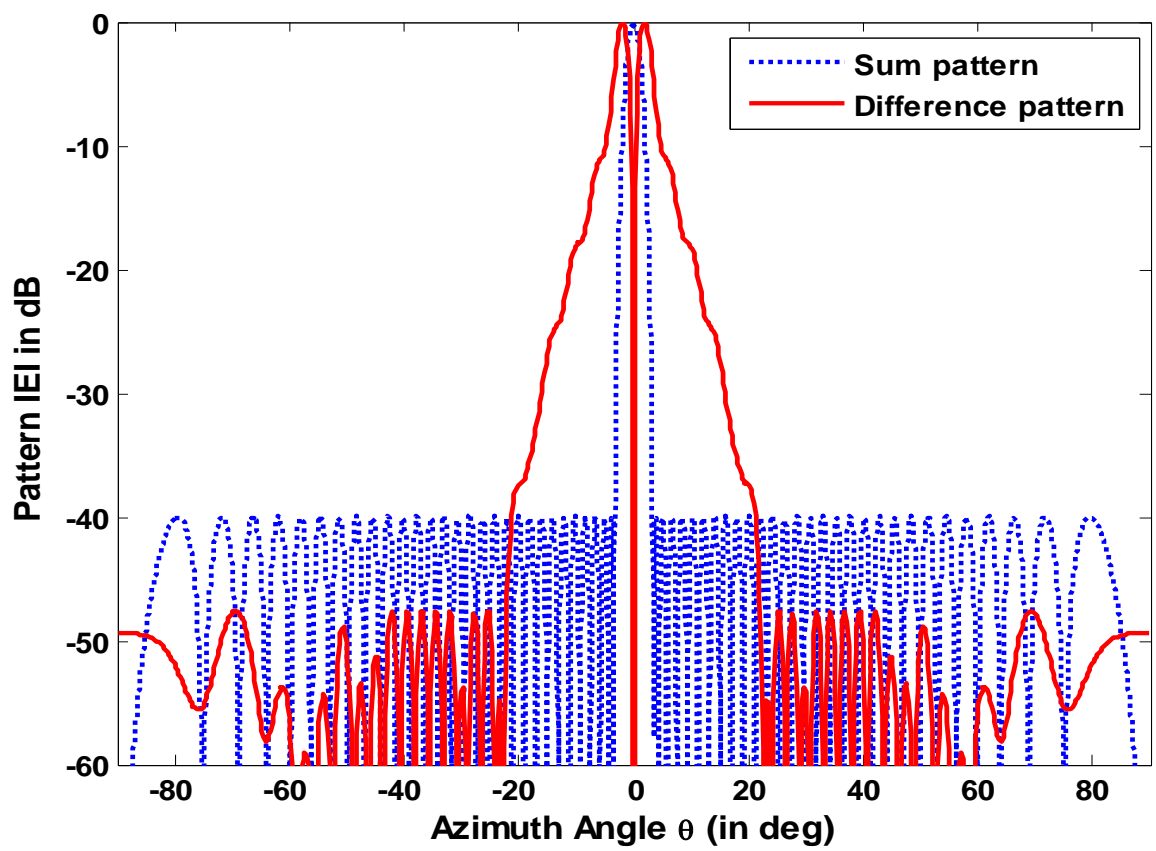

Figure: 10 Sum pattern for a 60 elements Dolph-chebyshev array space factor with SLL=-40dB and the corresponding optimized difference pattern for $\mathrm{P}=8$ subarrays 


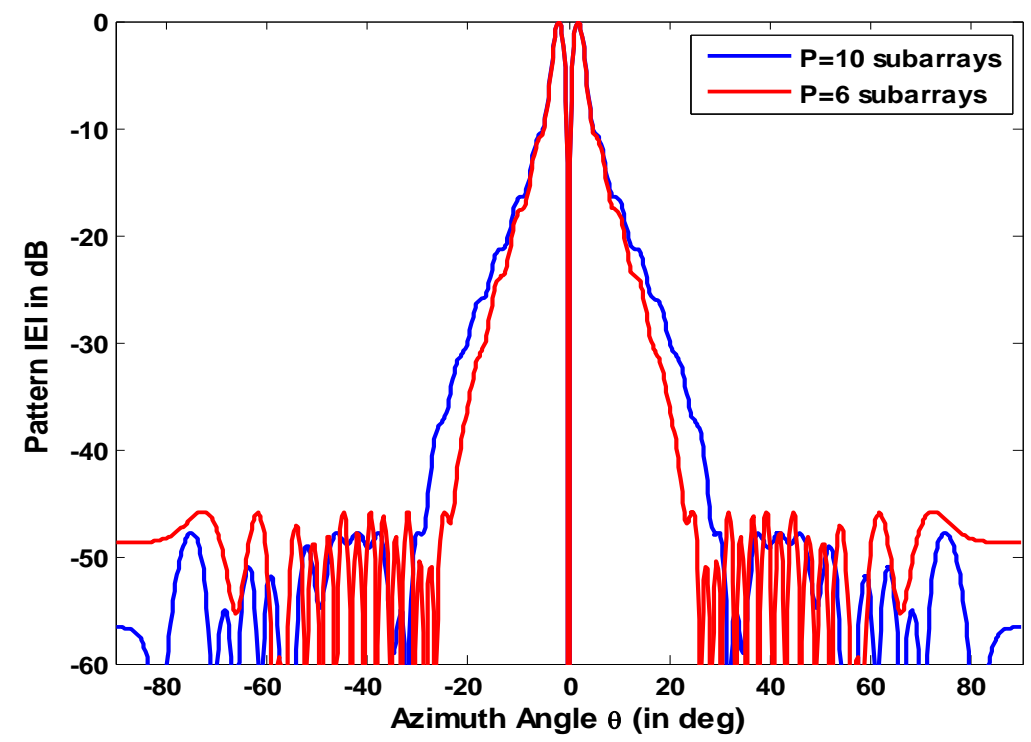

Figure: 11 optimized difference patterns for various values of $\mathrm{P}$ obtained by DE when the sum pattern is predetermined from the Dolph-chebyshev synthesis.

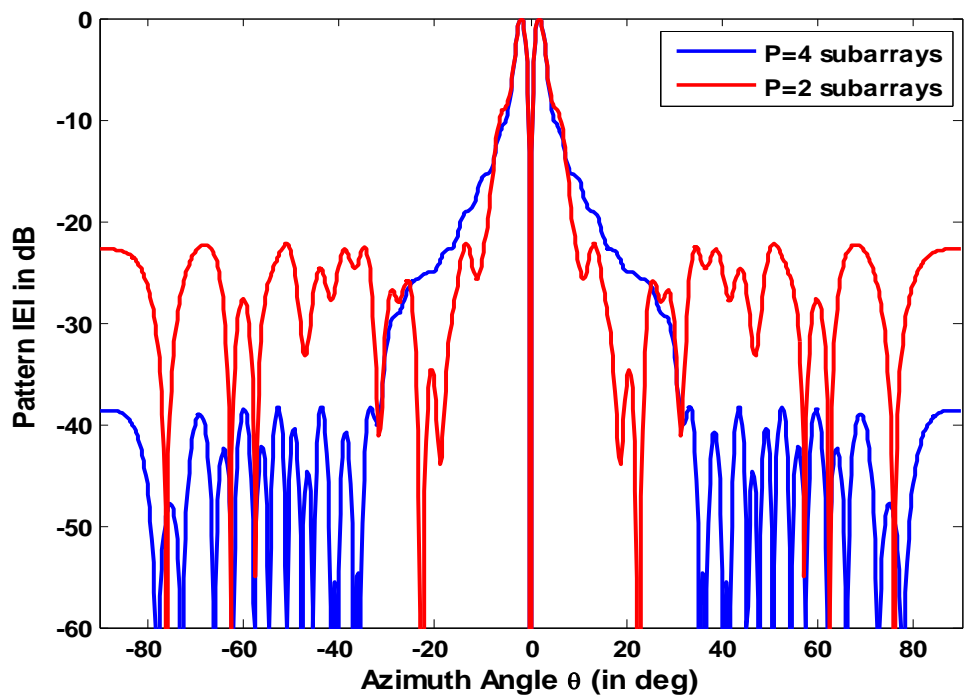

Figure: 12 optimized difference patterns for various values of $\mathrm{P}$ obtained by DE when the sum pattern is predetermined from the Dolph-chebyshev synthesis

Table: 3 Subarray configurations of 60 element with SLL $=-40 \mathrm{~dB}$

\begin{tabular}{|c|c|}
\hline Subarray number & Optimal clustering in to subarrays and here showing only half of the array \\
\hline $\mathrm{P}=10$ & {$[7,2,10,1,1,10,1,1,1,10,1,1,10,1,10,1,1,1,10,10,1,10,10,1,1,1,4,9,6,8]$} \\
\hline $\mathrm{P}=8$ & {$[8,7,5,1,3,3,1,1,1,2,1,1,1,1,1,2,1,1,3,6,2,4,2,3,1,4,5,7,7,8]$} \\
\hline $\mathrm{P}=6$ & {$[1,2,3,5,6,4,6,6,4,6,6,5,5,6,6,6,6,6,4,5,6,6,6,6,5,5,6,2,2,1]$} \\
\hline $\mathrm{P}=4$ & {$[3,2,1,2,2,4,1,2,2,1,1,1,1,1,1,4,1,4,1,1,1,4,4,2,4,2,1,4,3,3]$} \\
\hline $\mathrm{P}=2$ & {$[2,2,2,1,1,1,1,1,1,1,1,1,2,1,2,1,2,1,1,1,1,1,1,1,1,1,1,2,2,2]$} \\
\hline
\end{tabular}

Table: 4 Subarray weights for the arrays described in table 3

\begin{tabular}{|c|c|c|c|c|c|}
\hline & $\mathrm{P}=10$ & $\mathrm{P}=8$ & $\mathrm{P}=6$ & $\mathrm{P}=4$ & $\mathrm{P}=2$ \\
\hline G1 & 0 & 0.9857 & 0.2182 & 0.9992 & 0.3818 \\
\hline G2 & 0.7642 & 0.9789 & 0.6445 & 0.9487 & 0.2244 \\
\hline G3 & 0 & 1.0000 & 0.8784 & 0.3980 & \\
\hline G4 & 0.8928 & 0.9702 & 0 & 0.9984 & \\
\hline G5 & 1.0000 & 0.8533 & 0 & & \\
\hline G6 & 0.5874 & 0 & 0 & & \\
\hline G7 & 0.2797 & 0.6053 & & & \\
\hline G8 & 0.1618 & 0.2088 & & & \\
\hline G9 & 0.8666 & & & & \\
\hline G10 & 0 & & & & \\
\hline
\end{tabular}


Table: 5 Optimized difference pattern FSLL's obtained by DE with various values of P sub arrays for SLL = $40 \mathrm{~dB}$

\begin{tabular}{|c|c|c|}
\hline Indices $\mathrm{P}$ & Number of elements 40 & Number of elements 60 \\
\hline $\mathrm{P}=10$ & $-54.79 \mathrm{~dB}$ & $-54.97 \mathrm{~dB}$ \\
\hline $\mathrm{P}=8$ & $-54.53 \mathrm{~dB}$ & $-54.91 \mathrm{~dB}$ \\
\hline $\mathrm{P}=6$ & $-54.43 \mathrm{~dB}$ & $-51.04 \mathrm{~dB}$ \\
\hline $\mathrm{P}=4$ & $-41.45 \mathrm{~dB}$ & $-54.67 \mathrm{~dB}$ \\
\hline $\mathrm{P}=2$ & $-30.46 \mathrm{~dB}$ & $-35.16 \mathrm{~dB}$ \\
\hline
\end{tabular}

\section{Conclusion}

In the present context of growing need in the field of electromagnetic problems a relatively simple and straight forward optimization method Differential Evolution Algorithm has been demonstrated. By employing the above, jamming and EMI problems can be reduces effectively. The design of monopulse antennas for which a newly proposed process based on subarray configuration has been reported and discussed with the help of latest results. The method has been checked with several array configurations and successfully synthesizes the sum and difference pattern in a linear array antenna with sufficiently ultra sidelobe level. Hence, the optimal solutions found by DE are equivalently as good as those obtained in 60 element array. Numerical simulation results of several array synthesis problems shows that the DES performs much better than PSO, Ant Colony Optimization and most of the other methods.

\section{References}

[1]. R. S. Elliot, "Antenna Theory and Design,” Prentice-Hall, New York, 1981.

[2]. D. A. MC Namara, "synthesis of Sub-Arrayed Monopulse Linear Arrays through Matching of Independently Optimum Sum and Differences Excitations," Proc. IEE Microwave Antennas Propagation., Vol. 135, No. 5, PP. 371-374, October 1988.

[3]. C.A. Balanis, "Antenna Theory Analysis and Design,” John Wiley and Sons, INC., United States of America, 1982.

[4]. G.S.N. Raju, Antennas and Wave Propagation, Pearson Education, 2005.

[5]. P. Lopez, F. Ares, J.A. Rodriguez and E. Moreno, "Subarray weighting for the difference patterns of monopulse antennas: joint optimization of subarray configurations and weights," IEEE Trans. Antennas and Propagation, Vol.49, No. 11, PP. 1606-1608, Nov. 2001.

[6]. D. G. Kurup, M. Himdi and A. Rydberg, "synthesis of uniform amplitude unequally spaced antenna arrays using the differential evolution algorithm," IEEE Transactions on Antennas and Propagation, Vol. 51, No. 9, PP. 2210-2217, September 2003.

[7]. D A. Shindman, "An optimization technique for sum and difference array factors," IEEE Transactions on Aerospace and Electronic Systems, Vol. 40, No. 1, PP. 360-370, January 2004.

[8]. O. M. Bucci, L. Caccavale and T. Isernia, "Optimal far-field focusing of uniformly spaced array subject to arbitrary upper bounds in non target directions," IEEE Transactions on Antennas and Propagation, Vol. 50, No. 11, PP. 1539-1554, November 2002.

[9]. O. M. Bucci, M. D'urso and T. Isernia, "Optimal synthesis of difference patterns subject to arbitrary sidelobe bounds by using arbitrary array antennas," Proc. IEE Microwave Antennas and Propagation, Vol. 152, No. 3, PP. 129-137, June 2005.

[10]. M. Alvarez-Folgueiras, F. Arespena and J. Rodriguez-Gonzales, "Optimal compromise among sum and difference patterns in monopulse antennas: Use of subarrays and distributions with common aperture tail," Journal of electromagnetic waves and applications, Vol. 23, Nos. 17-18, PP. 2301-2311, 2009.

[11]. P. Rocca, R. Azaro, L. Manica and A. Massa, "A hybrid approach to the synthesis of subarrayed monopulse linear arrays," IEEE Trans. Antennas and Propagation, Vol. 57, PP. 280-283, Jan. 2009.

[12]. Y. Chen, S. Yang and Z. Nie, "The application of a modified differential evolution with strategy adaptation," IEEE Antennas and Wireless Propagation Letters, Vol.10, 2011.

Dr. T Vidhyavathi received her B.Tech degree from JNTU Hyderabad in the department of Electronics and

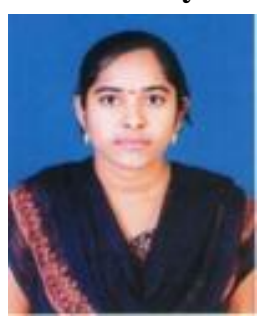
Communication Engineering during the year 2006 and the Master of Technology in Radar and Microwave Engineering from Andhra University College of Engineering (A) in the year 2008. Her Ph.D degree awarded in the year 2015 from the department of Electronics and Communication Engineering, Andhra University College of Engineering (A). Currently, she is working as an Assistant Professor in the department of ECE, Gayatri Vidya Parishad College of Engineering (A), Visakhapatnam, Andhra Pradesh, India. Her Research interests include Antenna Array Processing, Electromagnetic Theory and Wave Propagation, EMI/EMC, Soft Computing and Engineering applications of convex optimization. She is a member of IEEE and also a life member of SEMCE (India).

Dr. G S N Raju received his B.E, M.E with distinction also first rank from Andhra University and Ph.D from

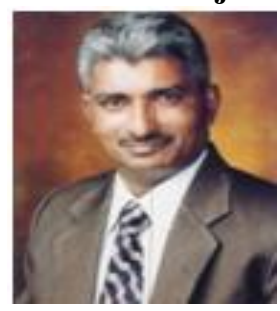

IIT- Kharagpur. At present, he is the Honorary Distinguished Professor in department of Electronics and Communication Engineering, AU College of Engineering (A). He was the former Vice - Chancellor of Andhra University. He is in teaching and research for the last 35 years in Andhra University. He guided 49 Ph.D.s in the fields of Array Antennas, Electromagnetics and Wavepropagation, EMI/EMC, Microwave and Radar Communications, Electronic circuits. Published about 394 technical papers in National/ International Journals/ Conference Journals and transactions. He is the recipient of The State Best Teacher Award' from the Government of Andhra Pradesh in 1999, 'The Best 
Researcher Award' in 1994, 'Prof. Aiya Memorial National IETE Award' for his best Research guidance in 2008 and Dr. Sarvepalli Radhakrishnan Award for the Best Academician of the year 2007, He was a visiting Professor in the University of Paderborn and also in the University Karlsruhe, Germany in 1994. He held the positions of Principal, Andhra University College of Engineering (A), Visakhapatnam, Chief Editor of National Journal of Electromagnetic Compatibility. Prof. Raju has published 11 textbooks on Antennas and Wave Propagation, Electromagnetic Field Theory and Transmission Lines, Electronics Devices and Circuits, Microwave Engineering, Radar Engineering and Navigational Aids. Prof. Raju has been the best faculty performer in Andhra University with the performance index of $99.37 \%$.

Dr. G V K Varma received the B.Tech. degree from the Indian Institute of Technology Delhi, New Delhi,

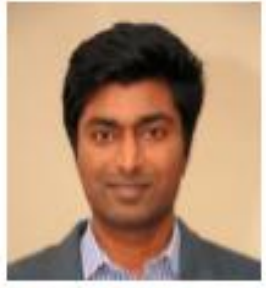
India, the Master's degree in electrical engineering from Texas A\&M University, College Station, Texas and the Ph.D. degree in electrical engineering from the University of Texas at Dallas, Richardson, Texas. He is currently working in Qualcomm, San Diego as a Senior Engineer. His research interests are in the broad areas of wireless communications, software engineering, algorithms and networking. 